\title{
PRESERVING THE ASTRONOMICAL SKY
}

Edited by: R. J. COHEN and W. T. SULLIVAN, III
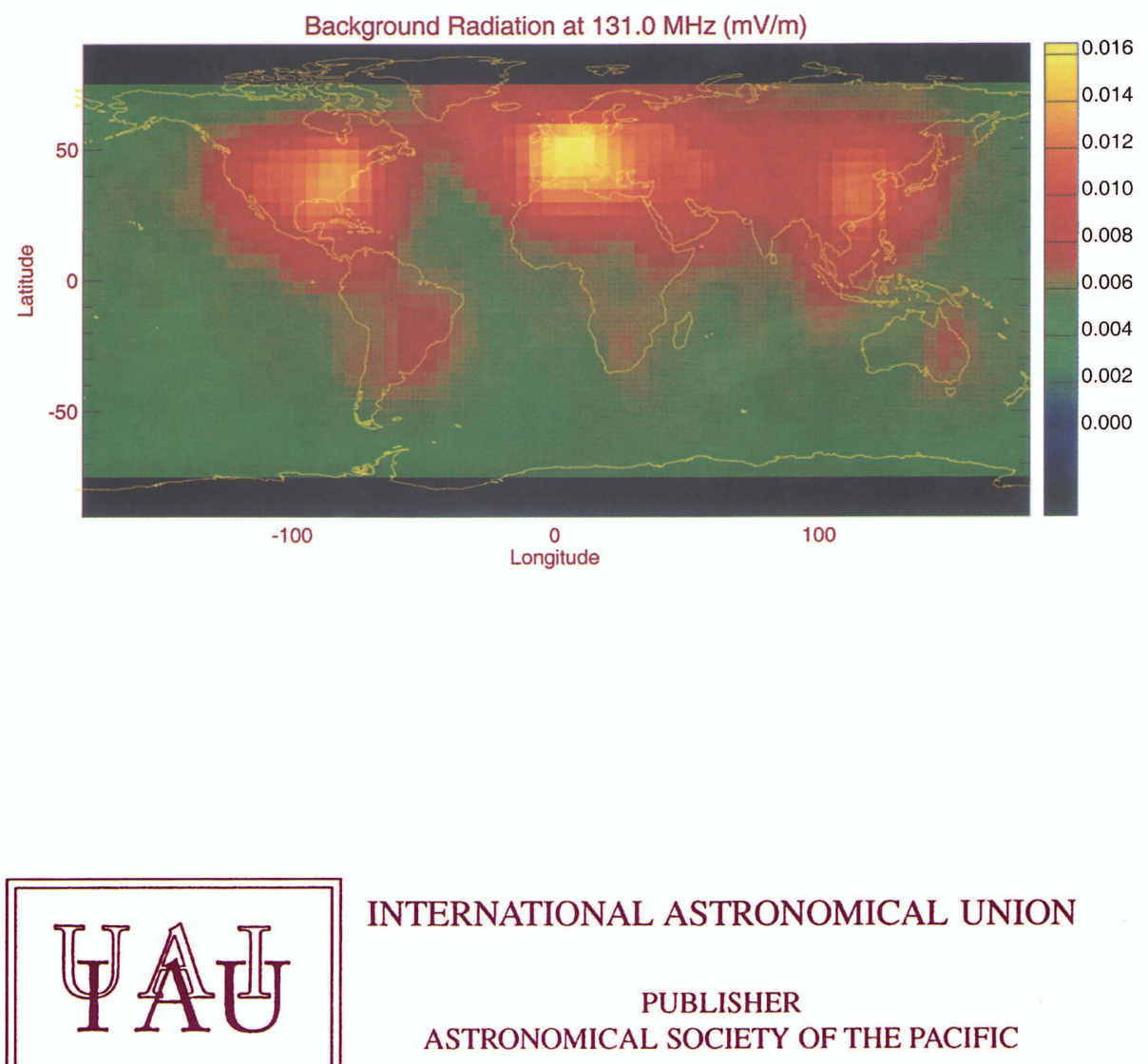

INTERNATIONAL ASTRONOMICAL UNION

PUBLISHER

ASTRONOMICAL SOCIETY OF THE PACIFIC 


\section{PRESERVING THE ASTRONOMICAL SKY}

IAU SYMPOSIUM VOLUME 196

\section{COVER ILLUSTRATION:}

Future radio telescopes will have to be located in radio-quiet parts of the world (pp. 199 and 271). The global distribution of radio background emission at $131 \mathrm{MHz}$ shows how few radio-quiet regions there are at low frequencies. The quantity plotted is the median root-mean-square electric field measured by the FORTE satellite (http://forte.lanl.gov/) at 800-840 km altitude, averaged over several months and all local times. The centre frequency is $131 \mathrm{MHz}$ and the bandwidth is $1 \mathrm{MHz}$. The FORTE satellite is a joint project of the Los Alamos National Laboratory and the Sandia National Laboratory, under the auspices of the United States Department of Energy. Persons interested in more information on radio-frequency backgrounds and other aspects of FORTE data should contact the project leader, Dr. Abram R. Jacobson (ajacobson@lanl.gov). 


\section{THE ASTRONOMICAL SOCIETY OF THE PACIFIC 390 Ashton Avenue - San Francisco, California - USA 94112-1722 Phone: (415) 337-1100 Fax: (415) 337-5205 \\ E-Mail: catalog@aspsky.org \\ Web Site: www.aspsky.org}

\section{Publisher}

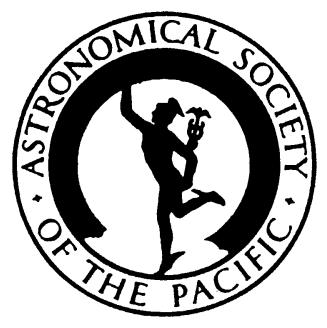

\section{ASP CONFERENCE SERIES - EDITORIAL STAFF}

Managing Editor: D. H. McNamara

Associate Managing Editor: J. W. Moody
LaTeX-Computer Consultant: T. J. Mahoney

Production Manager: Enid L. Livingston

PO Box 24453, 211 KMB, Brigham Young University, Provo, Utah, 84602-4463

Phone: (801) 378-2111 Fax: (801) 378-4049 E-Mail: pasp@byu.edu

ASP CONFERENCE SERIES PUBLICATION COMMITTEE:

$\begin{array}{ll}\text { Alexei V. Filippenko } & \text { Geoffrey Marcy } \\ \text { Ray Norris } & \text { Donald Terndrup } \\ \text { Frank X. Timmes } & \text { C. Megan Urry }\end{array}$

A listing of all other ASP Conference Series Volumes and IAU Volumes published by the ASP is cited at the back of this volume 


\section{INTERNATIONAL ASTRONOMICAL UNION}

98bis, Bd Arago - F-75014 Paris - France

Tel: +331 $43258358 \quad$ E-mail: iau @iap.fr

Fax: +33 143252616 Web Site: www.iau.org

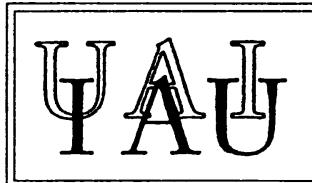

\section{PRESERVING THE ASTRONOMICAL SKY}

Proceedings of the $196^{\mathrm{TH}}$ Symposium of the IAU

held in

United Nations Vienna International Conference Centre in conjunction with UNISPACE III

at Vienna, Austria

12-16 July 1999

Edited by

R. J. Cohen

University of Manchester, Jodrell Bank Observatory, Macclesfield Cheshire, United Kingdom

and

W. T. Sullivan, III

University of Washington, Department of Astronomy, Seattle, Washington, USA 
C 2001 by International Astronomical Union All Rights Reserved

No part of the material protected by this copyright notice may be reproduced or utilized in any form or by any means - graphic, electronic, or mechanical including photocopying, taping, recording or by any information storage and retrieval system, without written permission from the IAU.

Library of Congress Cataloging in Publication Data

Main entry under title

Card Number: 2001091699

ISBN: 1-58381-078-1

IAU Publications - First Edition

Published on behalf of IAU by Astronomical Society of the Pacific

Printed in United States of America by Sheridan Books, Chelsea, Michigan 


\section{Contents}

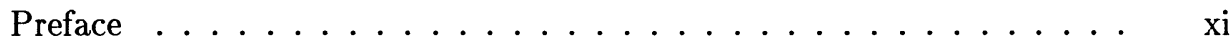

List of Participants ................. xiii

Organizing Committees $\ldots \ldots \ldots \ldots \ldots \ldots$ xvii

\section{Part 1. Introduction}

Opening Remarks . . . . . . . . . . . . . . . . . 3

Hans $J$. Haubold

Remarks on the Effort to Preserve the Astronomical Sky . . . . . . . 7

Robert P. Kraft (delivered by W. T. Sullivan, III)

History, Strategy and Status of IAU Actions _ . . . . . . . . 10

J. Andersen

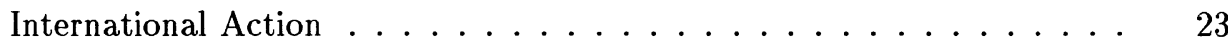

D. McNally

\section{Part 2. Threats to Optical Astronomy}

Light Pollution: Changing the Situation to Everyone's Advantage . . .

David L. Crawford

Controlling Light Pollution in Chile: A Status Report . . . . . . . .

Malcolm G. Smith

Light Pollution: How High-Performance Luminaires Can Reduce It . . .

Christian Remande and members of the Lighting Applications

Department, R-Tech Company (delivered by M. Gillet)

The International Commission on Illumination - CIE: What It Is and How

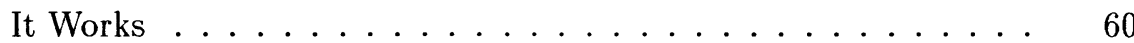

Christine Hermann

Recent CIE Activities on Minimizing Interference to Optical Observations

Duco A. Schreuder 
Guide on the Limitation of the Effects of Obtrusive Light from Outdoor Lighting Installations ...............

Nigel Pollard

Why Astronomy Needs Low-Pressure Sodium Lighting . . . . . . . . . .

Christian B. Luginbuhl

Methods and Results of Estimating Light Pollution in the Flemish Region

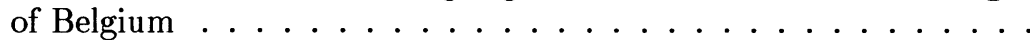

J. Vandewalle, Dirk Knapen, Tim Polfliet and H. Dejonghe

The Artificial Sky Brightness in Europe Derived from DMSP Satellite Data

P. Cinzano, F. Falchi, C. D. Elvidge and K. E. Baugh

Using DMSP Night-Time Imagery to Evaluate Lighting Practice in the American Southwest . . . . . . . . . . . . .

Christian B. Luginbuhl

Light Pollution and Energy Loss from Cairo . . . . . . . . . . . .

A. I. I. Osman, S. Isobe, S. Nawar and A. B. Morcos

Local and National Regulations on Light Pollution in Italy . . . . . . .

Valentina Zitelli, Mario Di Sora and Federico Ferrini

Japanese Government Official Guideline for Reduction of Light Pollution

Syuzo Isobe

Outdoor Lighting Ordinances: Tools to Preserve the Night Sky . . . . .

Donald R. Davis

Plan of the Modification of Public Lighting in Frosinone in Accordance with the Rule for the Limitation of Light-Pollution and Power

Consumption ..................

M. Di Sora

Sky Glow Measurements in the Netherlands ............

Duco A. Schreuder

Light Pollution in Quebec ..................

Yvan Dutil

Observing Conditions from 1988 to 1999 at Huairou Solar Observing

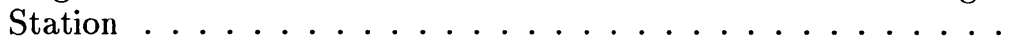

Yuanyong Deng and Yihua Yan

The Situation of Light Pollution in Germany . . . . . . . . . .

Andreas Hänel

Economic Imperative versus Efforts for Preserving an Astronomical Site

Hakim L. Malasan, Moch. Arief Senja, Bambang Hidayat and Moedji

Raharto

Work for the Reduction of Light Pollution in Turkey . . . . . . . .

Z. Aslan 
Astronomical Sites in the Ukraine: Current Status and Problems of

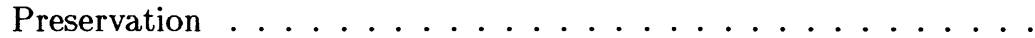

I. B. Vavilova, V. G. Karetnikov, A. A. Konovalenko, O. O. Logvinenko,

G. I. Pinigin, N. V. Steshenko, V. K. Tarady and Ya. S. Yatskiv

Chelmos (Aroania): a New European Telescope Site for the 2.3-m

Telescope of the National Observatory of Athens . . . . . . . 160

D. Sinachopoulos, F. Maragoudaki, P. Hantzios, E. Kontizas and

R. Korakitis

The Impact of Light Pollution on a Proposed Automatic Telescope

Network (ATN) and Vice Versa . . . . . . . . . . . 163

John R. Mattox, Stefan Wagner, Gino Tosti and Kent Honeycutt

Bridges and Outdoor Lighting $\ldots \ldots \ldots \ldots$

Arthur Upgren

Search for and Protection of Astronomical Sites in Developing Countries

François R. Querci and Monique Querci

Aviation and Jet Contrails: Impact on Astronomy . . . . . . . . .

H. Pedersen

\section{Part 3. Space Debris}

The Space Debris Environment - Past and Present . . . . . . . .

W. Flury

UN Discussions of Space Debris Issues $\ldots \ldots \ldots \ldots \ldots$

Luboš Perek

Impact of Space Debris and Space Reflectors on Ground-Based Astronomy 188

D. McNally

Observations of Artificial Space Objects in Lviv Astronomical Observatory

Jeva Vovchyk, Jaroslav Blagodyr and Olexandr Logvinenko

\section{Part 4. Threats to Radio Astronomy}

The Future of Radio Astronomy: Options for Dealing with Human

Generated Interference . . . . . . . . . . . . . .

R. D. Ekers and J. F. Bell

Radio Astronomy and the International Telecommunications Regulations

Brian Robinson

Radio Astronomy and the Radio Regulations . . . . . . . . . .

R. J. Cohen

World Radio Conference WRC-2000 . . . . . . . . . . . . .

Klaus Ruf

Radio Astronomy and Recent Telecommunications Trends . . . . . . .

Tomas E. Gergely 
Protection of Millimetre-Wave Astronomy . . . . . . . . . . .

Masatoshi Ohishi

Utilization of the Radiofrequency Spectrum above $1 \mathrm{GHz}$ by Passive Services. . . . . . . . . . . . . . . .

Juan R. Pardo, Pierre J. Encrenaz and Daniel Breton

Radio Astronomy in the European Regulatory Environment . . . . . . . 264

R. J. Cohen

Preserving Radio Astronomy in Developing Nations . . . . . . . . .

G. Swarup and C. R. Subramanya

Steps to Establish International Radio Quiet Zones . . . . . . . . . . . .

Harvey Butcher

A Potential Site for the World's Largest Single Dish, FAST . . . . . .

B. Peng, R. G. Strom and R. Nan

Techniques for Coping with Radio Frequency Interference . . . . . . .

J. R. Fisher

Radio Interference and Ejecting Techniques at Beijing Astronomical

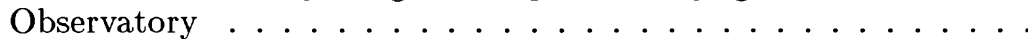

$X$. Zhang, T. Piao, B. Peng and X. Wang

Radio Interference Monitoring and Databases . . . . . . . . . . .

W. van Driel

Fixed and Mobile RFI Search Facilities at Medicina . . . . . . . .

S. Montebugnoli, G. Tomassetti, C. Bortolotti and M. Roma

RFI Sentinel 2

S. Montebugnoli, M. Cecchi, C. Bortolotti, M. Roma and S.Mariotti

Radio Interference in Astronomical Observatories of China . . . . . . 307

B. Peng, R. Nan, T. Piao, D. Jiang, Y. Su, R. G. Strom, S. Wu, X. Zhang,

L. Zhu and X. Liu

Measurements of Radio Interference at Solar Radio Stations

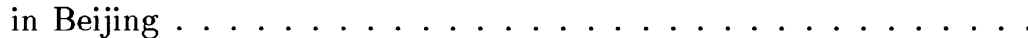

Yihua Yan, Qijun Fu, Yuying Liu and Zhijun Chen

Analysis of Solar Radio Observations and the Influence of Interference .

Yihua Yan, Huirong Ji, Qijun Fu, Yuying Liu and Zhijun Chen

GPS Satellite Interference in Hungary . . . . . . . . . . . .

T. Borza and I. Fejes

Protecting Space-Based Radio Astronomy . . . . . . . . . . . . .

V. Altunin

Origin of Major L-Band Interference Received by the HALCA Space Radio

Telescope . . . . . . . . . . . . . . . .

S. Yu. Lioubtchenko, M. V. Popov, H. Hirabayashi and H. Kobayashi 
Part 5. Outreach

Saving Our Skies: Communicating the Issues to the Media . . . . . . 343

Richard West and Claus Madsen

Light Pollution: Education of Students, Teachers and the Public . . . . 353

John R. Percy

The Light Pollution Programme in Greece . . . . . . . . . . . . .

M. Metaxa

Educating the Public about Light Pollution . . . . . . . . . . . 363

Syuzo Isobe, Shiomi Hamamura and Christopher D. Elvidge

The Cultural Value of Radio Astronomy . . . . . . . . . . . . . . 369

Woodruff T. Sullivan, III

Educating the Public About Interference to Radio Observatories . . . . 377

David G. Finley

Part 6. Outcomes

Optical Workshop Report: Statements Relative to Environmental

Protection for Optical Astronomy . . . . . . . . . . . .

Radio Workshop Report: Technical Methods and Strategies for Mitigating

Radio Frequency Interference (RFI) . . . . . . . . . .

389

J. R. Fisher

Radio Workshop Report: Public Awareness of Radio Interference . . . .

David G. Finley

Postscript .......................

R. J. Cohen

Appendix 1. S196 Proposal to UNISPACE III . . . . . . . . . . .

Appendix 2. OECD Global Science Forum, Task Force on Radio

Astronomy and the Radio Spectrum: Terms of Reference,

March 2001.......................

Appendix 3. Abbreviations .................. 401

Author Index ........................... 405

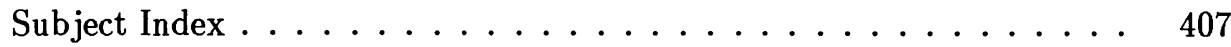

